M. Mirzaei, P. Ripka, J. Vyhnanek, A.Chirtsov, V. Grim: RotationalEddy Current Speed Sensor,

IEEE Transactions on Magnetics vol.55, no.9, pp.1-10, Sept. 2019, Art no.4003710, 10.1109/TMAG.2019.2918163

\title{
Rotational Eddy Current Speed Sensor
}

\author{
Mehran Mirzaei, Pavel Ripka, Jan Vyhnanek, Andrey Chirtsov, and Vaclav Grim \\ Faculty of Electrical Engineering, Czech Technical University, Prague, 16627, Czech Republic
}

\begin{abstract}
A novel eddy current speed sensor is de veloped to measure rotational speed of conductive objects. The se nsor consists of on e excitation coil and two pick up coils around rotating cylinder or rod. The sensor does not use magnetic yoke. For the an aly si s and experimental verification we used $30 \mathrm{~mm}$ diameter non-magneticaluminum and also magnetic solid iron cylinders. The calculated and measured speed range is until $1200 \mathrm{rpm}$. 2D analy tical method is de veloped to calculate sensor performance. $2 \mathrm{D}$ finite element is a $\mathrm{lso}$ used for simulations to compare results with 2D analytical method. 3D finite element an alys is is requ ired to tak int o account significant 3D effects due to the air coils configuration. The experimental resul ts are presented at different steady state $s$ pe eds. The calculations results are compared with measurements to validate theoretical models and sensor performance. The eddy current $s$ pe ed sensor shows high linearity even at low spe eds. For ferromagnetic rods we suggest novel double-layer configur ation: $n$ on -m ag netic conductive ring or shell on top of the iron rod minimizes the influence of the permeability changes. The main advantage of the $n$ ovel sensor is that it has neither mechanical nor electrical con tact to the rotating rod.
\end{abstract}

Index Terms - Rotational speed sensor, eddy current, 2D analytical method, 2D and 3D finite element method, air coil.

\section{INTRODUCTION}

$\mathrm{T}$ HE SPEED sensors are key component of control and monitoring systems in linear and rotating machines [1][2]. Optical speed sensors are representatives of wellestablished nonmagnetic technology. Magnetic speed sen sors utilize variable reluctance effect, eddy current effect and Hall effect [3]. The contactless magnetic speed sensors are better option for industrial speed sensors application in harsh environment with high probability of dirt and dust in comparis on with nonmagnetic speed sensors. Existing magnetic speed sensors usually use permanent magnets or current carrying coils as excitation source. Permanent magnets are either mounted on the moving part or stationary - in both cases the sensors suffer from the temperature depen dence of the magnet properties and they are also sensitive to the change in the dis tance between moving and stationary part [4]-[5].

Speed probe based on eddy currents and reluctance variations in metallic body moving in the field of permanent magnet using Hall sensor or pick up coil were pres ente $d$ for some applications in [5]-[6]. A speed sensor based on high sensitivity of an amorphou s core with ring shape mounted on solid iron E shape core for magnetic field excitation was shown in [7], which has disadvantage of the necessity of using amorphous core with zero-magnetostriction and sharp rectangular $B-H$ curve. Different structures of eddy current speed sensor with non-perpendicular and perpendicular coils were presented with analytical models based on Fourier transform in [8]-[10]. Speed sensor based on linear v ariable differential transformer (LVDT) configuration with ferrite yoke is presented in [11], which was presented for flat type moving part using outcomes of [8]-[10]. Non-ferromagnetic moving conductors such as aluminum are only used in [5][11], which are not complicated for measurement and simulations. An eddy current linear speed sensor with

Corresponding author: M. Mirzaei (e-mail: mirzameh@fel.cvut.cz). axisymmetric structure was developed and measured at variable linear speeds with ferromagnetic iron rod [12], which magnetic relative permeability was measured and estimated for precise simulations and analysis. Rotational eddy current speed sensor could be very appropriate option for some applications such as turbochargers [13]-[15], which is problematic for conventional speed sensor.

In our linear speed sensor we use single coil excitation coil with AC current and two antiserially connected pick up coils for the measurement [12] without using ferromagnetic yoke as back iron for flux. In his paper we suggest similar scheme for rotational speed sensing. Despite the similar principle, the description of the rotational sensor requires different approach.

Fast and precise 2D analytical methods are presented to calculate excitation coil inductance and coupling inductances and induced voltages into the pick up coils taking into account eddy currents in the rotating conductive rod caused by alternating current and moving conductive rod speed for a rotating model using Fourier series. General closed-form equations are also obtained for output results. 2D and 3D finite element method (FEM) simulations with consideration of rotating part speed are also presented to compare with analytical calculations and consider 3D effects. Different relative magnetic permeabilities are considered for the rotating solid iron part. Cylindrical aluminum rod and solid ferromagnetic iron rod are both used in the measurement for rotating part and the experimental results are compared with the analytical and FEM calculations. The induced voltag es of pick-up coils are measured with lock-in amplifier.

The main novelty of the present paper is double-layer configuration: non-magnetic conductive ring on top of the iron rod minimizes the influence of the permeability changes of the rod.

\section{Model and CoIls Configurations}

Fig. 1 shows 3D model of rotating rod and speed sensor 
M. Mirzaei, P. Ripka, J. Vyhnanek, A.Chirtsov, V. Grim: RotationalEddy Current Speed Sen sor,

IEEE Transactions on Magnetics vol.55, no.9, pp.1-10, Sept. 2019, Art no.4003710, 10.1109/TMAG.2019.2918163

coils. The middle coil is considered as excitation coil and le $\mathrm{ft}$ and right hand sides coils are pick up coils in the first configuration. It is also possible to use left and righthand side antis erially connected coils as excitation coils and middle co il as pick up coil. Rotating rod is solid iron or aluminum. The axial length of rotating rod is considered large enough in comparis on with coils dimensions.

It is clear that induced voltage in the pickup coils in both above mentioned configurations is zero at zero speed because the net flux linkage is zero.

Fig. 2 and Table I show parameters and dimensions of rotational speed sensor. Parameters $r_{\mathrm{i}}, r_{\mathrm{wi}}, r_{\mathrm{wo}}, g, \theta_{\mathrm{o}}, \theta_{\mathrm{i}}, L_{\mathrm{i}}, \sigma_{\mathrm{al}}$, $\sigma_{\mathrm{i}}$ and $\mu_{\mathrm{i}}$ are outer radius of rotating rod, inner radius of coils, outer radius of coils, gap between coils and rotating rod, outer angle of coils, inner angle of coils, straight part length of coils in axial z-direction, aluminum electrical conductivity, iron electrical conductivity and iron relative magnetic permeability, respectively.

TABLE I

ROTATING SPEED SENSOR PARAMETERS

\begin{tabular}{cc}
\hline \hline Parameters & Values \\
\hline$I$ & $172.36 \mathrm{~mA}$ \\
$N$ & 50 \\
$r_{\mathrm{i}}$ & $15 \mathrm{~mm}$ \\
$r_{\mathrm{wi}}$ & $16.25 \mathrm{~mm}$ \\
$r_{\mathrm{wo}}$ & $18.25 \mathrm{~mm}$ \\
$g=r_{\mathrm{wi}}-r_{\mathrm{i}}$ & $1.25 \mathrm{~mm}$ \\
$\theta_{\mathrm{o}}$ & $46 \mathrm{Deg}$. \\
$\theta_{\mathrm{i}}$ & $33.4 \mathrm{Deg}$. \\
$L_{\mathrm{i}}$ & $30 \mathrm{~mm}$ \\
$\sigma_{\mathrm{al}}$ & $21.5 \mathrm{MS} / \mathrm{m}$ \\
$\sigma_{\mathrm{i}}$ & $5.54 \mathrm{MS} / \mathrm{m}$ \\
$\mu_{\mathrm{ri}}$ & 100 \\
\hline \hline
\end{tabular}

\section{2D MODELING}

\section{A. Analytical}

The Maxwell equations are used to compute speed sensor performance [16]-[17]. Final differential equations in cylindrical coordinate have only axial z-component of magnetic vector potential, $A_{z}$ and current density, $J_{z}$ because of 2D configuration. Magnetic flux density and magnetic field streng th have only radial and azimuthal components, $B_{\mathrm{r}}, B_{\theta}, H_{\mathrm{r}}$ and $H_{\theta}$, respectively:

$$
\begin{aligned}
& {\left[\begin{array}{l}
B_{r} \\
B_{z}
\end{array}\right]=\left[\begin{array}{ll}
\mu & 0 \\
0 & \mu
\end{array}\right]\left[\begin{array}{l}
H_{r} \\
H_{z}
\end{array}\right]} \\
& \frac{1}{r}\left(\frac{\partial\left(r H_{\theta}\right)}{\partial r}-\frac{\partial H_{r}}{\partial \theta}\right)=J_{z}, \frac{1}{r}\left(\frac{\partial\left(r B_{r}\right)}{\partial r}+\frac{\partial B_{\theta}}{\partial \theta}\right)=0 \\
& {\left[\begin{array}{l}
\frac{1}{r} \frac{\partial J_{z}}{\partial \theta} \\
-\frac{\partial J_{z}}{\partial r}
\end{array}\right]=\left[\begin{array}{l}
-\sigma \frac{d B_{r}}{d t} \\
-\sigma \frac{d B_{\theta}}{d t}
\end{array}\right],\left[\begin{array}{l}
B_{r} \\
B_{\theta}
\end{array}\right]=\left[\begin{array}{l}
\frac{1}{r} \frac{\partial A_{z}}{\partial \theta} \\
-\frac{\partial A_{z}}{\partial r}
\end{array}\right]}
\end{aligned}
$$

conductivity, respectively.

The induced eddy current in the rotating rod with electrical conductivity, $\sigma$ due to the iron rod speed, $\omega_{\mathrm{r}}$ must be considered in the equations [18]-[19]:

$$
J_{z}=-\sigma\left(\frac{\partial A_{z}}{\partial t}+\frac{d \theta}{d t} \frac{\partial A_{z}}{\partial \theta}\right)=-\sigma\left(\frac{\partial A_{z}}{\partial t}+\omega_{r} \frac{\partial A_{z}}{\partial \theta}\right)
$$

The computational model is divided to four parts. Parts 1,2 , 3 and 4 are rotating rod region, air region between rotating rod and coils, coils region and air region beyond coils, respectively.

$$
\begin{aligned}
& \frac{1}{r} \frac{\partial}{\partial r}\left(r \frac{\partial A_{z, 1}}{\partial r}\right)+\frac{1}{r^{2}} \frac{\partial^{2} A_{z, 1}}{\partial \theta^{2}}=\mu_{1} \cdot \sigma\left(\frac{\partial A_{z, 1}}{\partial t}+\omega_{r} \cdot \frac{\partial A_{z, 1}}{\partial \theta}\right) \\
& \frac{1}{r} \frac{\partial}{\partial r}\left(r \frac{\partial A_{z, 3}}{\partial r}\right)+\frac{1}{r^{2}} \frac{\partial^{2} A_{z, 3}}{\partial \theta^{2}}=-\mu_{3} \cdot J_{s} \\
& \frac{1}{r} \frac{\partial}{\partial r}\left(r \frac{\partial A_{z, 2,4}}{\partial r}\right)+\frac{1}{r^{2}} \frac{\partial^{2} A_{z, 2,4}}{\partial \theta^{2}}=0
\end{aligned}
$$

where, $J_{\mathrm{s}}$ is the source current density in the coils.

The method of separation of variables (method of Fo u rier) is used to solve (3), (4) and (5) [16]-[17].

They are as sumed that magnetic fields change sinusoidal versus time and periodically in $\theta$-direction with period length $2 \pi$. Therefore derivations could be replaced as follows:

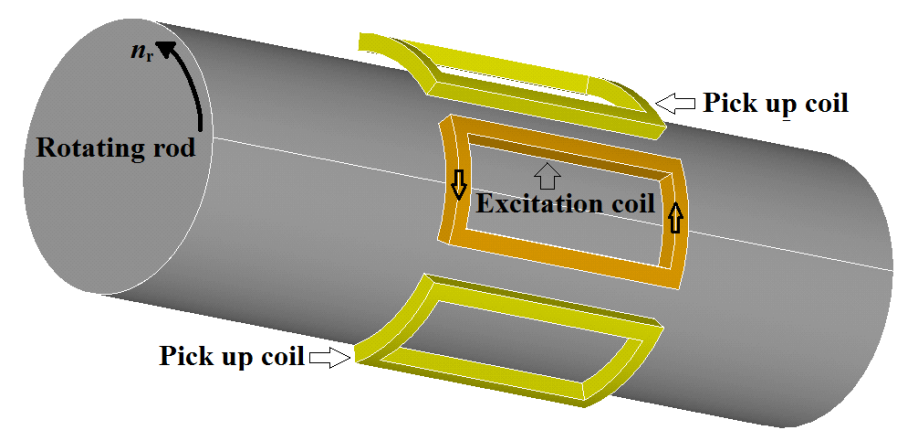

Fig. 1. 3D model of rotating eddy current speed sensor - First configuration of coils: one excitation coil and two antiserially connected pick up coils

where, $\mu$ and $\sigma$ are magnetic permeability and electrical 
M. Mirzaei, P. Ripka, J. Vyhnanek, A.Chirtsov, V. Grim: RotationalEddy Current Speed Sen sor,

IEEE Transactions on Magnetics vol. 55, no.9, pp.1-10, Sept. 2019, Art no.4003710, 10.1109/TMAG.2019.2918163

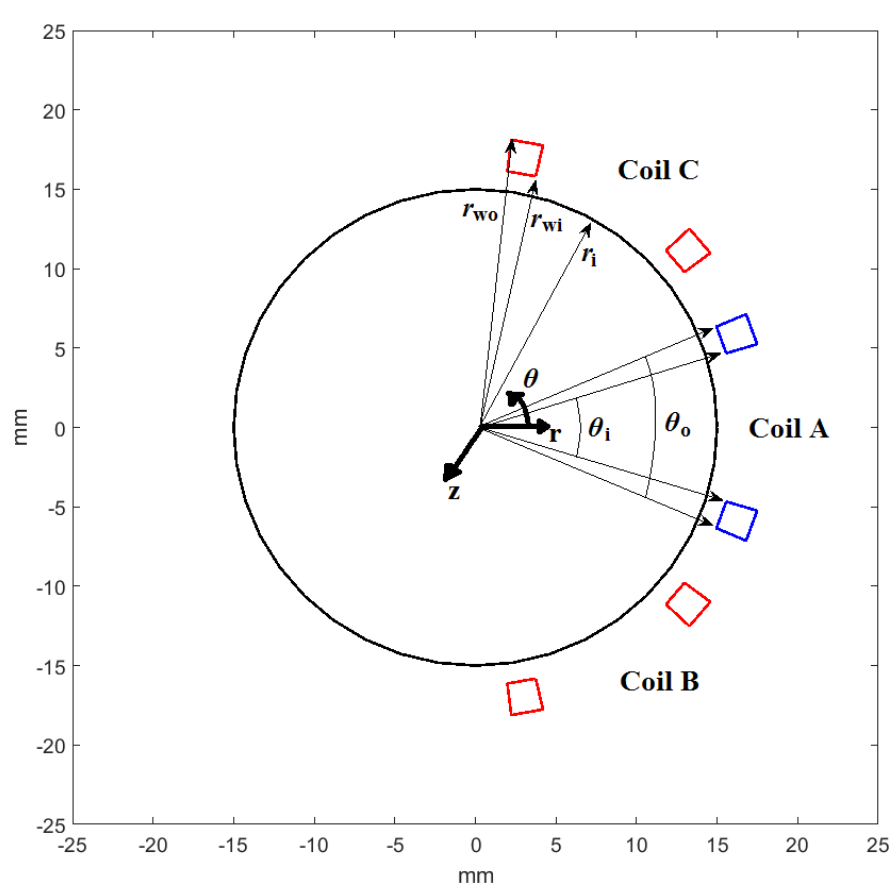

Fig. 2. 2D model and dimensions

$A_{z}=\Theta(\theta) \cdot R(r) \cdot T(t)$

$\Theta(\theta) \propto \exp (-j m \cdot \theta)$

$T(t) \propto \exp (j \omega \cdot t)$

$\frac{\partial A_{z}}{\partial t}=j \omega \cdot A_{z}$

$\frac{\partial A_{z}}{\partial \theta}=-j m \cdot A_{z}, \frac{\partial^{2} A_{z}}{\partial \theta^{2}}=-m^{2} \cdot A_{z}$

where, $\omega$ is angular frequency in $\mathrm{rad} / \mathrm{s}$.

The solutions versus radius, $r$ are as follows:

$$
\begin{aligned}
& A_{z, 1}=\sum_{m= \pm 1, \pm 2, \ldots}\left(C_{11} \operatorname{BesselI}\left(m_{1}, \gamma \cdot r\right)+C_{12} \operatorname{BesselK}\left(m_{1}, \gamma \cdot r\right)\right) \\
& \gamma=\sqrt{j \mu_{1} \sigma\left(\omega-m \cdot \omega_{r}\right)} \\
& A_{z, 2}=\sum_{m= \pm 1, \pm 2, \ldots}\left(C_{21} r^{m_{1}}+C_{22} r^{-m_{1}}\right) \\
& A_{z, 3}=\sum_{m= \pm 1, \pm 2, \ldots}\left(C_{31} r^{m_{1}}+C_{32} r^{-m_{1}}+A_{z, s}\right) \\
& A_{z, s}=\frac{\mu_{3} J_{\mathrm{m}}}{m^{2}-4} \cdot r^{2}\left(m_{1} \neq 2\right), A_{z, s}=\frac{\mu_{3} J_{\mathrm{m}}}{16} \cdot r^{2}(1-4 \log (r)) \\
& \left(m_{1}=2\right) \\
& A_{z, 4}=\sum_{m= \pm 1, \pm 2, \ldots}\left(C_{41} r^{m_{1}}+C_{42} r^{-m_{1}}\right) \\
& m_{1}=|m|
\end{aligned}
$$

where, $C_{11}, C_{12}, C_{21}, C_{22}, C_{31}, C_{32}, C_{41}$ and $C_{42}$ are constants and they are obtained by the following boundary conditions:

$$
\begin{aligned}
& A_{z, 1}(r=0)=0 \\
& A_{z, 1}\left(r=r_{\mathrm{i}}\right)=A_{z, 2}\left(r=r_{\mathrm{i}}\right), H_{\theta, 1}\left(r=r_{\mathrm{i}}\right)=H_{\theta, 2}\left(r=r_{\mathrm{i}}\right) \\
& A_{z, 2}\left(r=r_{\mathrm{wi}}\right)=A_{z, 3}\left(r=r_{\mathrm{wi}}\right), H_{\theta, 2}\left(r=r_{\mathrm{wi}}\right)=H_{\theta, 3}\left(r=r_{\mathrm{wi}}\right) \\
& A_{z, 3}\left(r=r_{\mathrm{wo}}\right)=A_{z, 4}\left(r=r_{\mathrm{wo}}\right), H_{\theta, 3}\left(r=r_{\mathrm{wo}}\right)=H_{\theta, 4}\left(r=r_{\mathrm{wo}}\right) \\
& A_{z, 3}(r=\infty)=0
\end{aligned}
$$

Parameter, $J_{\mathrm{m}}$ in (8) for coils region for single coil excitation and two antiserially connected coils could be calculated as follows, res pectively:

$$
\begin{aligned}
& J_{\mathrm{m}}=\frac{j}{m \pi} C_{J} \cdot J_{\mathrm{s}} \\
& J_{\mathrm{m}}=\frac{-1}{m \pi} C_{J} \cdot J_{\mathrm{s}} \cdot 2 \cdot \sin \left(\frac{m \theta_{d}}{2}\right) \\
& C_{J}=\left(\cos \left(m \frac{\theta_{i}}{2}\right)-\cos \left(m \frac{\theta_{o}}{2}\right)\right), \theta_{d}=\frac{2 \pi}{3} \\
& J_{\mathrm{s}}=\frac{N I}{\frac{\left(\theta_{o}-\theta_{i}\right)}{4} \cdot\left(r_{w o}^{2}-r_{w i}^{2}\right)}
\end{aligned}
$$

where, $N$ and $I$ are the number of turns per coil and current amplitude (Table I), respectively. The parameter $\theta_{\mathrm{d}}$ is the angle between coils $\mathrm{B}$ and $\mathrm{C}$ centers, which is considered equal to $120 \mathrm{Deg}$. It is considered that all coils have same dimensions in this paper. Mutual induced voltage, $V_{\mathrm{M}}$ and mutual inductance, $L_{\mathrm{M}}$ could be calculated as follows [18]:

$$
\begin{aligned}
& V_{M}=-\frac{d \Psi_{M}}{d t}=-j \omega N \oint A_{z} d l=-j \omega N \cdot L_{i} \cdot\left(A_{z}^{+}-A_{z}^{-}\right) \\
& L_{\mathrm{M}}=\frac{\Psi_{M}}{I}=\frac{N \cdot L_{i} \cdot \int\left(A_{z}^{+}-A_{z}^{-}\right) \cdot d s}{I \cdot a_{w}} \\
& a_{w}=\frac{\left(\theta_{o}-\theta_{i}\right)}{4} \cdot\left(r_{w o}^{2}-r_{w i}^{2}\right), d s=r \cdot d r \cdot d \theta
\end{aligned}
$$

where, $\Psi_{\mathrm{M}}$ is the total average mutual flux linkage over co ils $2 \mathrm{D}$ cross section area. The surface integration in (12) is applied on each coil cross section area. $A_{\mathrm{z}}^{+}$and $A_{\mathrm{z}}^{-}$are magnetic vector potentials in go and return paths of coil. Integration in (11) is for the ideal case with infinitesimal coil cross section. Integration in (12) is for the realcase of coil cros s section, which is averaged over coilcross section.

The differential voltage between left and right sides pick up coils (B and C in Fig. 2) is presented in (13) and (14). The differential voltage polarity changes as speed direction changes according to (13) and (14).

$$
V_{d}=V_{\mathrm{M}, l}-V_{\mathrm{M}, r}=j \omega \cdot\left(L_{\mathrm{M}, l}-L_{\mathrm{M}, r}\right) \cdot I
$$


M. Mirzaei, P. Ripka, J. Vyhnanek, A.Chirtsov, V. Grim: RotationalEddy Current Speed Sen sor,

IEEE Transactions on Magnetics vol.55, no.9, pp.1-10, Sept. 2019, Art no.4003710, 10.1109/TMAG.2019.2918163

$$
\begin{aligned}
& V_{d}=V_{\mathrm{M} l}-V_{\mathrm{M}, r}=j \omega N \cdot \sum_{m= \pm 1, \pm 2, \ldots}\left(C_{V} C_{J} \frac{4}{m} \sin \left(\frac{m \theta_{d}}{2}\right)\right) \\
& C_{V}=C_{31} \frac{r_{w o}^{m_{1}+2}-r_{w i}^{m_{1}+2}}{m_{1}+2}+C_{32} \frac{r_{w o}^{-m_{1}+2}-r_{w i}^{-m_{1}+2}}{-m_{1}+2}+\frac{\mu_{3} J_{\mathrm{m}}}{m^{2}-4} C \\
& C=\frac{r_{w o}^{4}-r_{w i}^{4}}{4}\left(m_{1} \neq 2\right), \\
& C_{V}=C_{31} \frac{r_{w o}^{m_{1}+2}-r_{w i}^{m_{1}+2}}{m_{1}+2}+C_{32} \log \left(\frac{r_{w o}}{r_{w i}}\right)+\frac{\mu_{3} J_{\mathrm{m}}}{16} C \\
& C=\frac{r_{w o}^{4}-r_{w i}^{4}}{4}- \\
& \left(r_{w o}^{4} \cdot\left(\log \left(r_{w o}\right)-\frac{1}{4}\right)-r_{w i}^{4} \cdot\left(\log \left(r_{w i}\right)-\frac{1}{4}\right)\right) \quad\left(m_{1}=2\right)
\end{aligned}
$$

Magnetic flux penetration in the rotating rod decreases with AC excitation current [19] at $30 \mathrm{~Hz}$ and $90 \mathrm{~Hz}$ and $+1200 \mathrm{rpm}$ speed due to the skin effect (Fig. 3- Fig. 4). Less flux penetration in the rotating rod at higher frequency causes les $\mathrm{s}$ differential mutual flux linkage and decreases speed sensitivity of the eddy current speed sensor (Table. II).

TABLE II

DifFerential Mutual Flux Linkage at DifFerent FreQuencies $+1200 \mathrm{RPM}$

\begin{tabular}{lc}
\hline \hline Frequency $(\mathrm{Hz})$ & $\begin{array}{c}\text { Flux linkage amplitude }(\mu \mathrm{Vs})- \\
\text { Iron / Aluminum }\end{array}$ \\
\hline 20 & $0.92 / 1.73$ \\
50 & $0.30 / 1.62$ \\
100 & $0.20 / 1.32$ \\
500 & $0.07 / 0.25$ \\
1000 & $0.04 / 0.10$ \\
\hline \hline
\end{tabular}

\section{B. FEM}

2D time transient finite element with consideration of motion is considered for numerical calculations [20]. Fig. 5 shows differential voltage amplitude results of antiserially connected pick up coils versus speed using 2D analytical and 2D FEM. The analytical calculations coincide well with 2D FEM, which shows accuracy of analy tical method. Exc ellent linearity is depicted in Fig. 5, which presents suitability of proposed sensor for speed meas urement. Higher frequency $90 \mathrm{~Hz}$ is more suitable for differential voltage measurement despite lower flux linkage at higher frequencies.

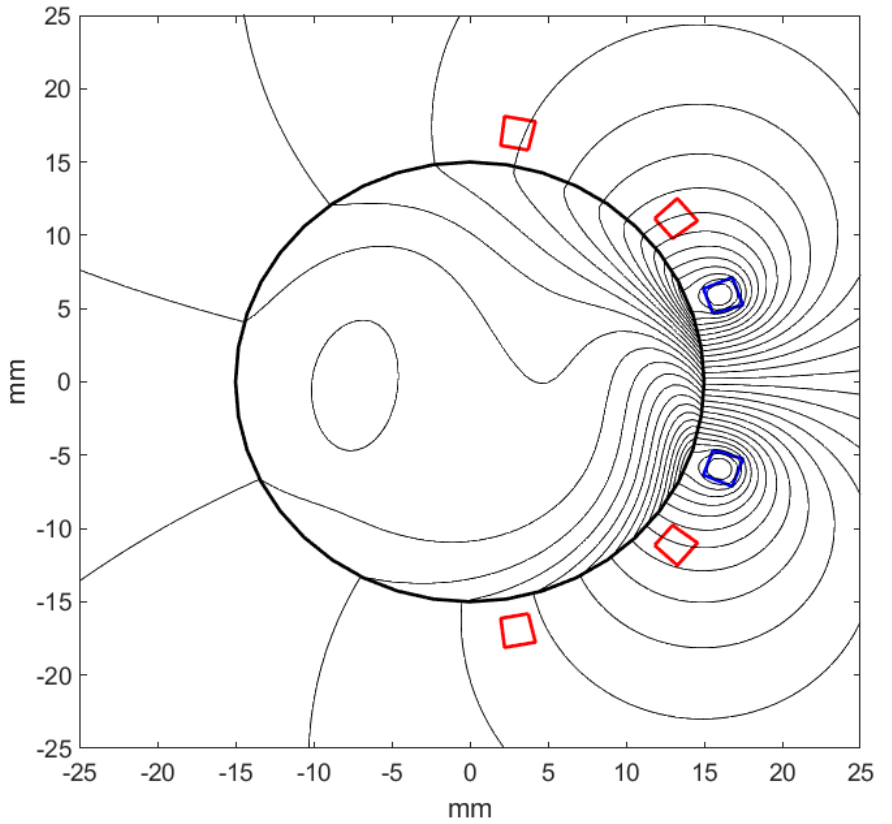

Fig. 3. Magnetic flux distribution at $30 \mathrm{~Hz}$ and $+1200 \mathrm{rpm}$ with rotating i ron rod - First configuration of coils: one excitation coil and two antiserially connected pick up coils - Analytical method

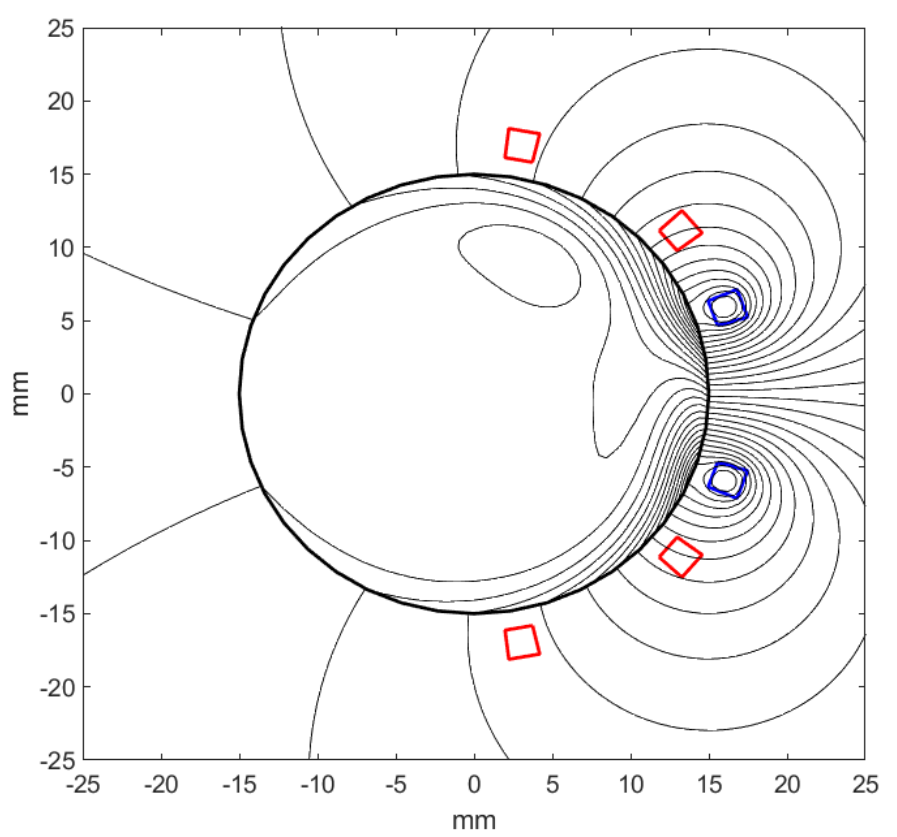

Fig. 4. Magnetic flux distribution at $90 \mathrm{~Hz}$ and $+1200 \mathrm{rpm}$ with rotating iron rod - First configuration of coils: one excitation coil and two antiserially connected pick up coils - Analytical method 
M. Mirzaei, P. Ripka, J. Vyhnanek, A.Chirtsov, V. Grim: RotationalEddy Current Speed Sen sor,

IEEE Transactions on Magnetics vol.55, no.9, pp.1-10, Sept. 2019, Art no.4003710, 10.1109/TMAG.2019.2918163

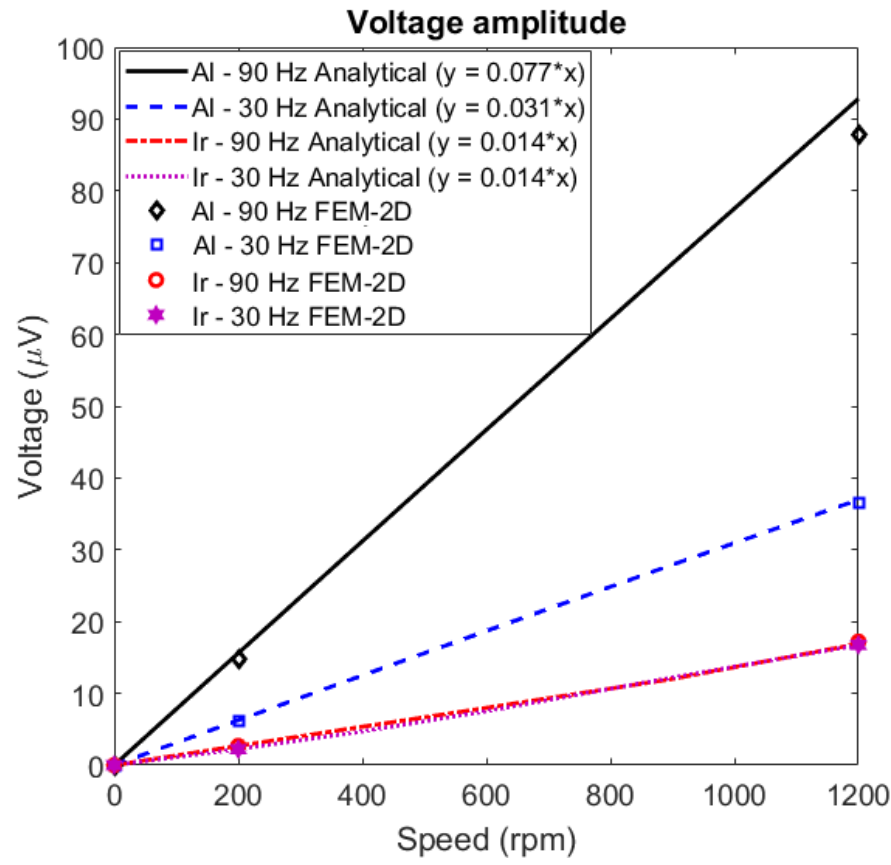

Fig. 5. Induced voltage versus speed for rotating aluminum rod (Al) and rotating iron rod (Ir) - Analytical versus 2D FEM

\section{Parameters variation}

Fig. 6 shows changing of magnetic flux distribution for rotating iron rod at $+1200 \mathrm{rpm}$ and $90 \mathrm{~Hz}$ and flux linkage between pick up coils and excitation coil with decreasing gap, $g$ (left) and increasing gap and coils angles, $\theta_{\mathrm{o}}$ and $\theta_{\mathrm{i}}$ (right). The difference between outer angle and inner angles of coils are considered constant in this paper. 3D graphs in Fig. 7 Fig. 8 related to variations of differential induced voltage amplitude versus gap and outer angle of coils, s how s e veral tendencies. Increasing outer angle of coils to maximum value, 60 Deg. increases coupling between excitation coil and pick up coils and differential induced voltage.

Decreasing gap does not have the same effect for the iro $n$ and aluminum rods as the flux leakage (non-coupled flux between the excitation coil and the pick up coils) increases with decreasing gap below $2 \mathrm{~mm}$ due to the high magnetic permeability of iron in comparison with aluminum. The maximum values of differential induced voltages are $30 \mu \mathrm{V}$ for rotating iron rod and $145 \mu \mathrm{V}$ for aluminum rod, res pectively. Optimumand efficient gap for rotating iron rod for maximum differential voltage is calculated $1.75-2 \mathrm{~mm}$ with outer angle of coils 60 Deg. (Fig. 7). Larger airgap is mechanically better and coils are safer when rod is rotatin $g$ at high speeds. Fig. 9 presents differential induced voltage versus relative permeability and conductivity for rotating iron rod. Decreasing magnetic relative permeability causes higher induced voltage similar to increasing iron electrical conductivity. It also shows that relative magnetic permeability has higher influence than electrical conductivity. This is a weak point of such sensor, as permeability is temperature dependent. The differential induced voltage versus electric al conductivity for nonmagnetic rotating $\operatorname{rod}\left(\mu_{\mathrm{r}}=1\right)$ is shown in
Fig. 10. It can be concluded, for example, copper is more efficient than aluminum.

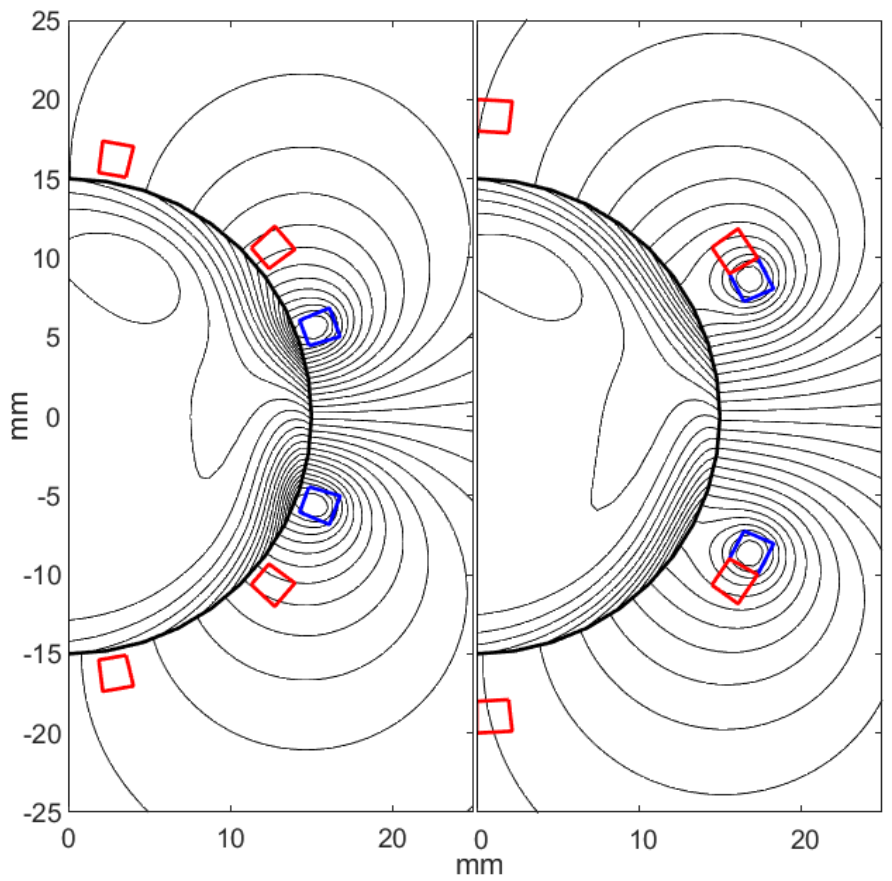

Fig. 6. Magnetic flux distribution at $90 \mathrm{~Hz}$ and $+1200 \mathrm{rpm}$ with rotating i ron rod -(left) modified gap between coils and rod, $g$ to $0.5 \mathrm{~mm}\left(r_{\mathrm{wi}}-r_{\mathrm{i}}=0.5 \mathrm{~mm}\right)$ and (right) modified gap, $g$ to $3 \mathrm{~mm}$ and also modified coil inner angle, $\theta_{\mathrm{i}}=$ 47.4 Deg. and modified coil outer angle $\theta_{0}=60$ Deg. - Analytical method

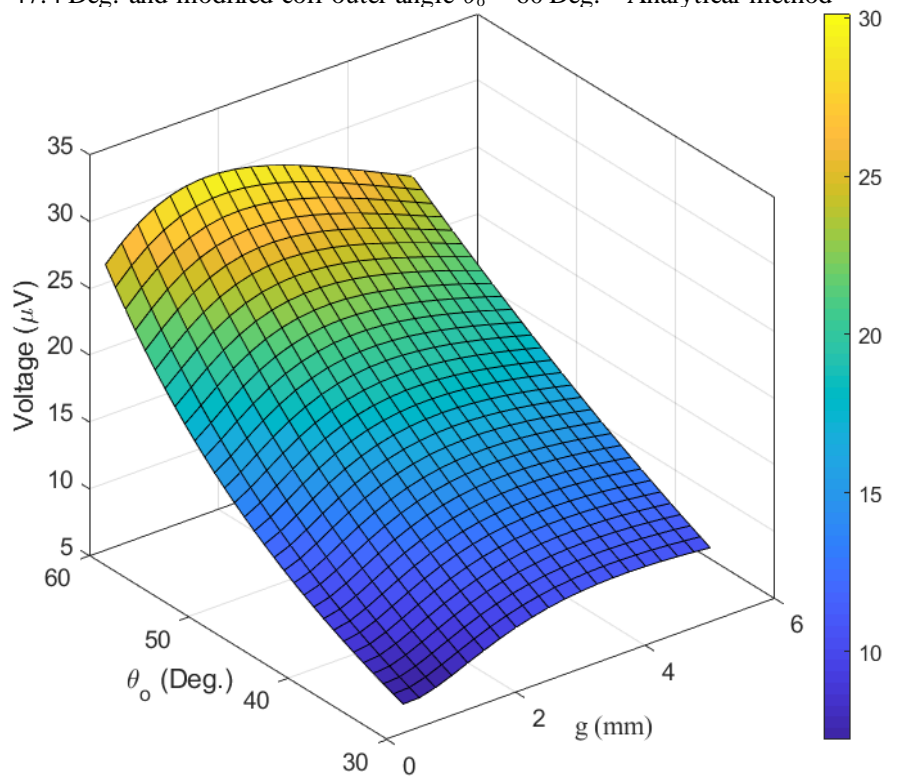

Fig. 7. Variation of differential voltage (amplitude) versus gap, $g$ and outer angle of coil, $\theta_{0}$ for rotating iron rod at $90 \mathrm{~Hz}$ and $1200 \mathrm{rpm}$ - Analytical method

Increasing frequency until $1000 \mathrm{~Hz}$ increases differential induced voltages for aluminum and iron rods as shown in Fig. 11. The curves for rotating iron rod and alumin u $\mathrm{m}$ rods do not have same tendency versus frequency because of high permeability of iron rod. Very high frequency is not recommended because the surface properties of conductive rods have large influence due to small penetration depth. The surfaces of conductive objects are us ually more affected, for 
M. Mirzaei, P. Ripka, J. Vyhnanek, A.Chirtsov, V. Grim: RotationalEddy Current Speed Sensor,

IEEE Transactions on Magnetics vol.55, no.9, pp.1-10, Sept. 2019, Art no.4003710, 10.1109/TMAG.2019.2918163

example, by manufacturing process and corrosion.

Skin depths are presented in Table. III at different frequencies. Larger skin depths cause larger differen tial flux linkage as shown in Table II and larger differentialvoltage.

Only linear magnetic modeling using initial permeability is considered in this paper due to the low magnetic fields in the sens or and nonlinearity and hysteresis effects are neglected. Relative magnetic permeability, $\mu_{\mathrm{ri}}=100$ (Table. I) is selected for the used rotating iron rod in this paper.

TABLE III

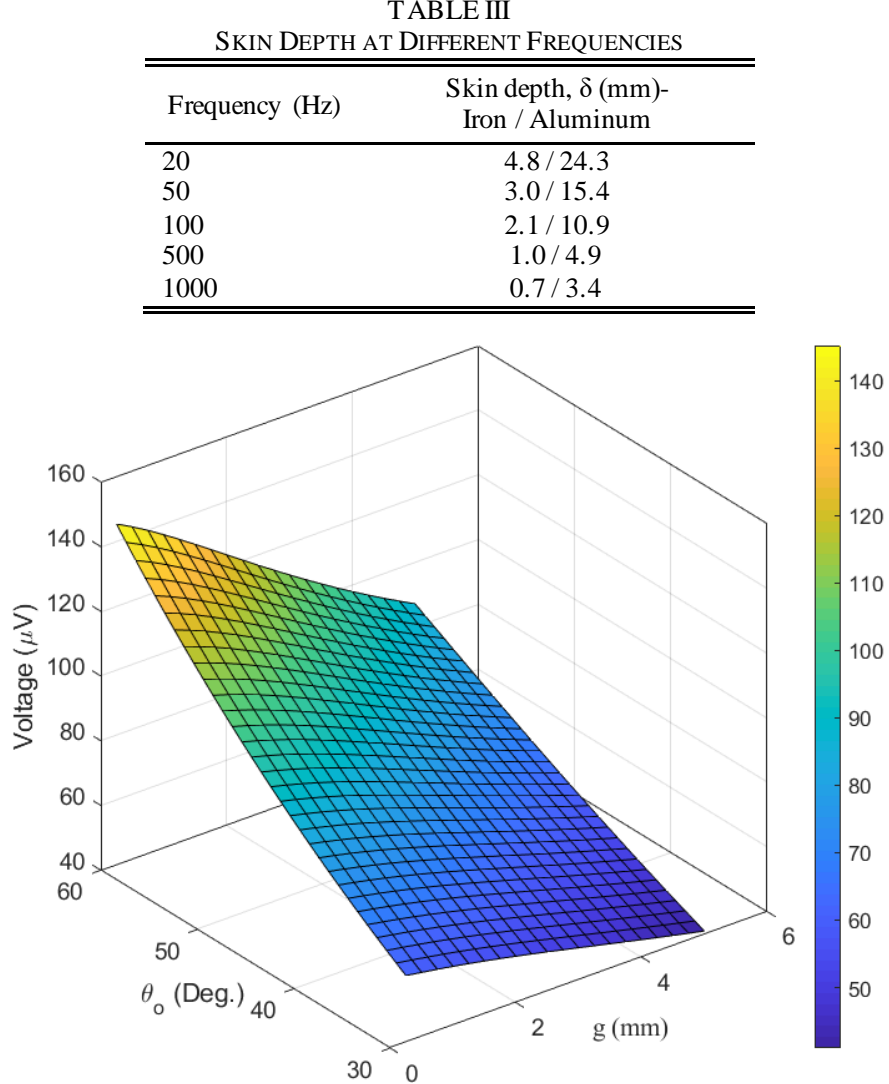

Fig. 8. Variation of differential voltage (amplitude) versus gap, $g$ and outer angle of coil, $\theta_{\mathrm{o}}$ for rotating aluminum rod at $90 \mathrm{~Hz}$ and $1200 \mathrm{rpm}$ - Analytical method

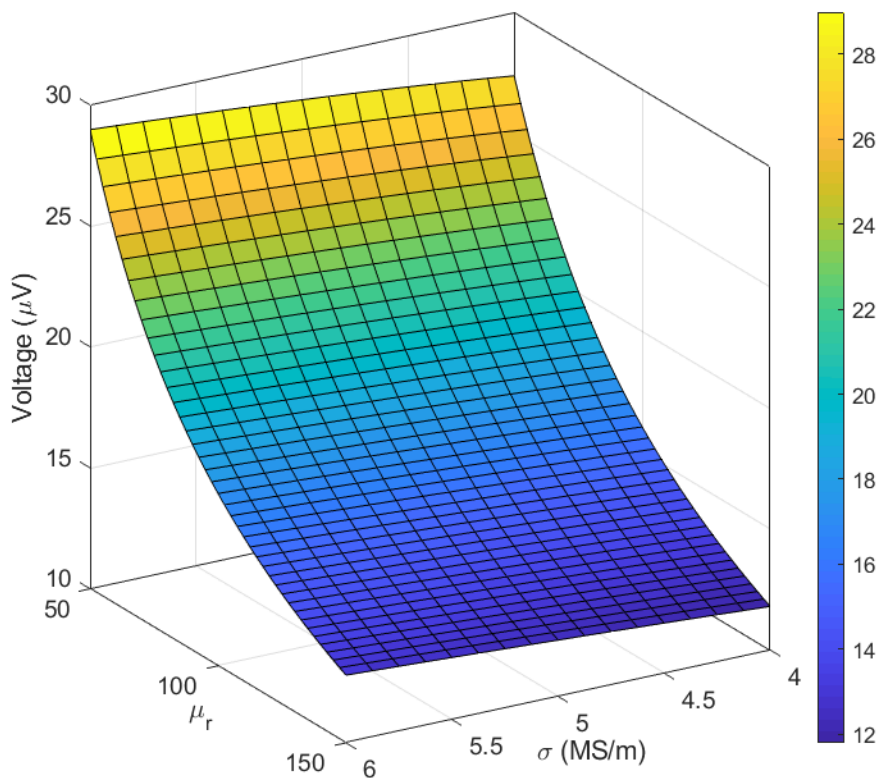

Fig. 9. Variation of differential voltage (amplitude) versus electrical conductivity and magnetic permeability for rotating iron rod at $90 \mathrm{~Hz}$ and $1200 \mathrm{rpm}\left(\theta_{\mathrm{o}}=46 \mathrm{Deg}\right.$. and $\left.g=1.25 \mathrm{~mm}\right)$ - Analytical method

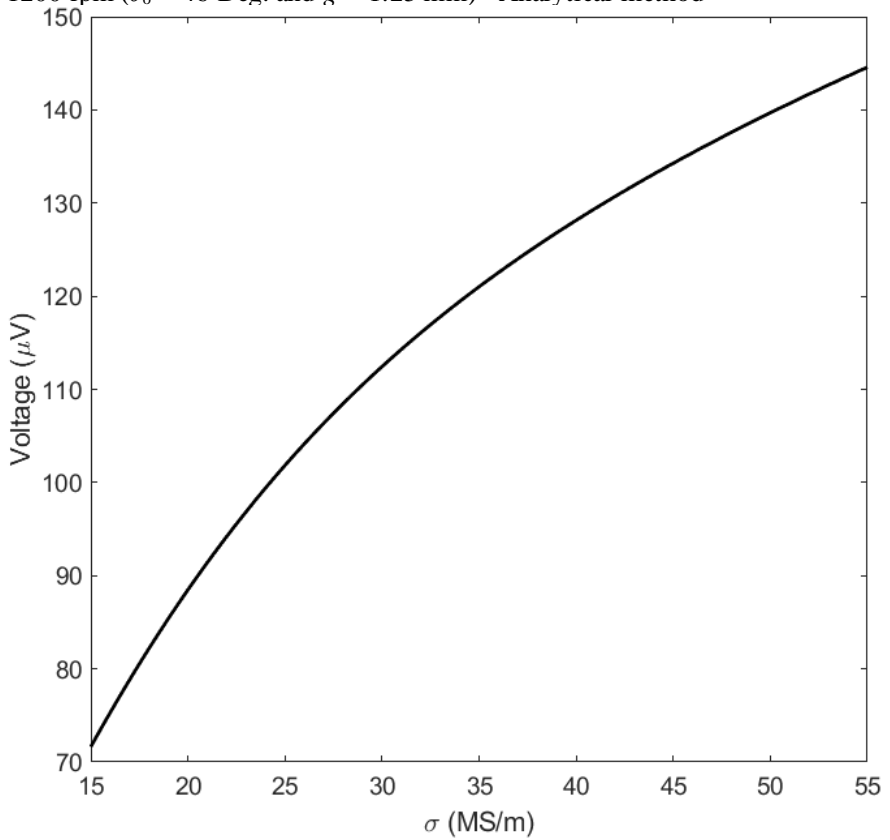

Fig. 10. Variation of differential voltage (amplitude) versus electrical conductivity for rotating aluminum rod at $90 \mathrm{~Hz}$ and $1200 \mathrm{rpm}\left(\theta_{\mathrm{o}}=46 \mathrm{Deg}\right.$. and $g=1.25 \mathrm{~mm}$ ) - Analytical method 
M. Mirzaei, P. Ripka, J. Vyhnanek, A.Chirtsov, V. Grim: RotationalEddy Current Speed Sen sor,

IEEE Transactions on Magnetics vol. 55, no.9, pp.1-10, Sept. 2019, Art no.4003710, 10.1109/TMAG.2019.2918163

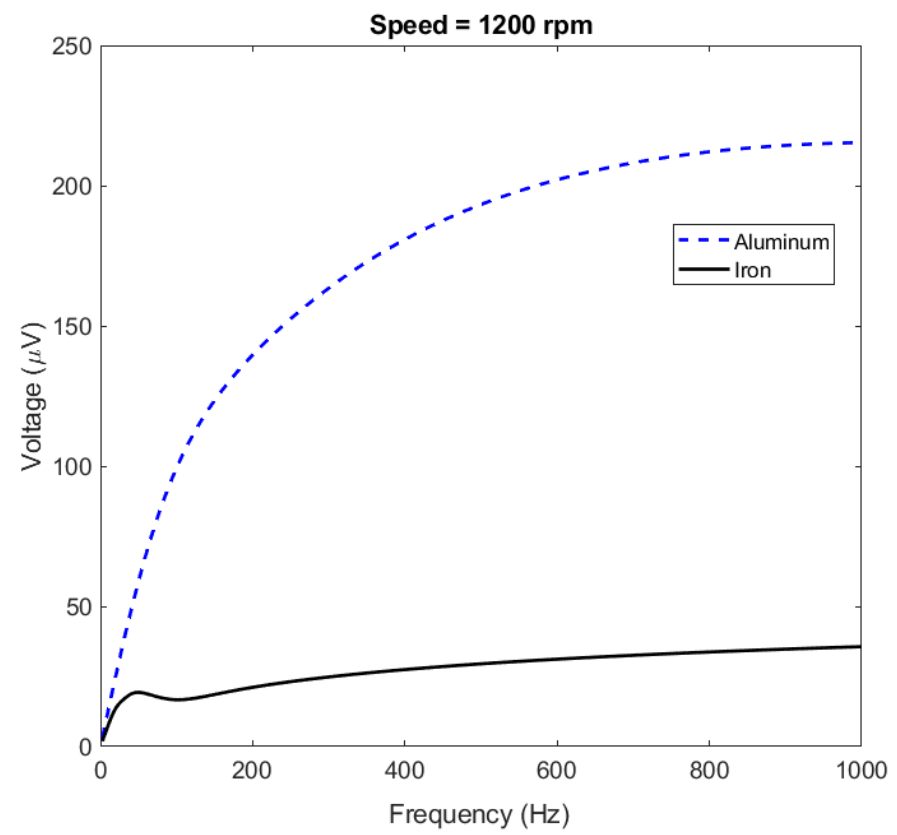

Fig. 11. Variation of differential voltage (amplitude) versus frequency at $1200 \mathrm{rpm}\left(\theta_{\mathrm{o}}=46 \mathrm{Deg}\right.$. and $\left.g=1.25 \mathrm{~mm}\right)$ - Analytical method

\section{3D FEM MODELING}

\section{A. Static rotor}

3D analysis is required for more accurate analysis of air coils eddy current speed sensor to take into account 3D effects such as 3D flux and eddy currents distributions in the conductive rotating rods. First 3D eddy current analysis (time harmonic) was done using Ansys/Maxwell software package [20] to evaluate 3D FEM model accuracy and parameters such as relative permeability of iron rod as mentioned in Table I. Calculated self inductances of excitation coil and induced voltages in one of the pick up coils at different frequencies are compared with experimental results in Tables VI and V. The calculated self inductances show high accuracy. Lower accuracy in the calculated mutual induced voltage is due to the higher sensitivity to pick up coils relative locations to excitation coil and also probably manufacturing tolerance.

TABLE IV

INDUCTANCE of EXCITATION COIL AT DifFERENT FREQUENCIES 3D FEM vs. EXP

\begin{tabular}{lc}
\hline \hline Frequency $(\mathrm{Hz})$ & $\begin{array}{c}\text { Inductance }(\mu \mathrm{H})- \\
\text { 3D FEM / Exp. }\end{array}$ \\
\hline 20 (iron core) & $137.2 / 135.0$ \\
50 (iron core) & $136.6 / 134.2$ \\
100 (iron core) & $135.8 / 132.4$ \\
100 (air core) & $98.9 / 95.0$ \\
500 (iron core) & $132.4 / 129.5$ \\
1000 (iron core) & $130.5 / 127.0$ \\
\hline \hline
\end{tabular}

TABLE V

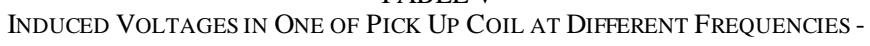
3D FEM Vs. EXP

\begin{tabular}{lc}
\hline \hline Frequency $(\mathrm{Hz})$ & $\begin{array}{c}\text { Induced voltage }(\mathrm{mV})- \\
\text { 3D FEM / Exp. }\end{array}$ \\
\hline 1 (iron core) & $0.0084 / 0.0076$
\end{tabular}

\begin{tabular}{ll}
100 (iron core) & $0.91 / 0.85$ \\
100 (air core) & $0.76 / 0.72$ \\
200 (iron core) & $1.86 / 1.76$ \\
\hline \hline
\end{tabular}

\section{B. Rotating rotor}

3D time transient FEM is used to take into account rod rotating motion [20]. Fig. 12 shows meshed model of conducting rods and coils. Half of the model is shown because of symmetry. Second orders elements are used. The sizes of elements are selected based on compromise between skin depth in the rotating rod and precise differential voltage calculations and also simulation time. The total axial length of rotating iron rod and rotating aluminum rod is considered $100 \mathrm{~mm}$ in the 3D FEM simulations.

\section{EXPERIMENTS}

Experimental set up are shown in Fig. 13 and Fig. 14. Lockin amplifier SR 830 is used to measure precisely s mall voltage of pick up coils and to minimize noise effects. Signal generator with internal resistance $50 \Omega$ is connected to the excitation coil. The aluminum or iron rod is connected to the shaft of DC motor. The speed range is between 0 to $1200 \mathrm{rpm}$. The axial length of rotating rods is considered $200 \mathrm{~mm}$ and $100 \mathrm{~mm}$ to evaluate its influence on the speed sensor performance.

Fig. 15 shows experimental results and 3D FEM calculations for differential induced voltage versus speed. The 3D FEM calculations coincide very well with experiments with small error(Fig. 16). Sensitivity of speed sensor is higher for rotating aluminumrod rather than iron rod. The linearity of eddy current speed sensor is excellent despite of simple structure of the proposed sensor. It has been verified that differential induced voltage are the same for two axial length $\mathrm{s}$ of rotating rods, $100 \mathrm{~mm}$ and $200 \mathrm{~mm}$.

The differential induced voltages are measured and calculated in 2D and 3D at $30 \mathrm{~Hz}$ and $90 \mathrm{~Hz}$. The 3D FEM results are higher than 2D analy tical and 2D FEM calculations (Fig. 5) due to the 3D effects in rotating iron rod. 3D FEM is more precise in comparison with measurement despite its longer simulations time. 3D modeling is necessary for air coil or yokeless magnetic devices. Time consuming 3D FEM models simulations s low down fast optimization and analysis, that is why 2D models, especially analy tical, are preferable at design stage. Dynamic response of the eddy current speed sensor is higher at $90 \mathrm{~Hz}$, which is important for acceleration and deceleration operations. The sensitivity of eddy current speed sensor for iron rod should be improved as most industrial applications are made with solid iron rather than non-magnetic stainless steel or aluminum. 
M. Mirzaei, P. Ripka, J. Vyhnanek, A.Chirtsov, V. Grim: RotationalEddy Current Speed Sen sor,

IEEE Transactions on Magnetics vol.55, no.9, pp.1-10, Sept. 2019, Art no.4003710, 10.1109/TMAG.2019.2918163

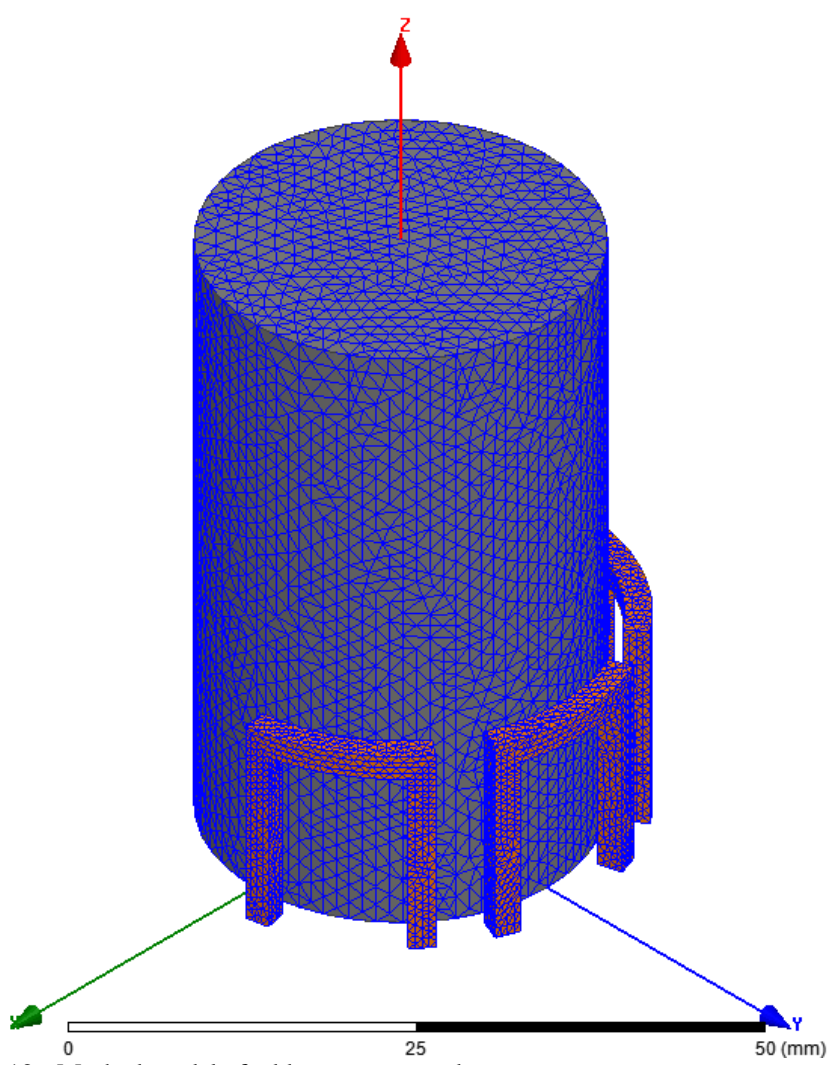

Fig. 12. Meshed model of eddy current speed sensor

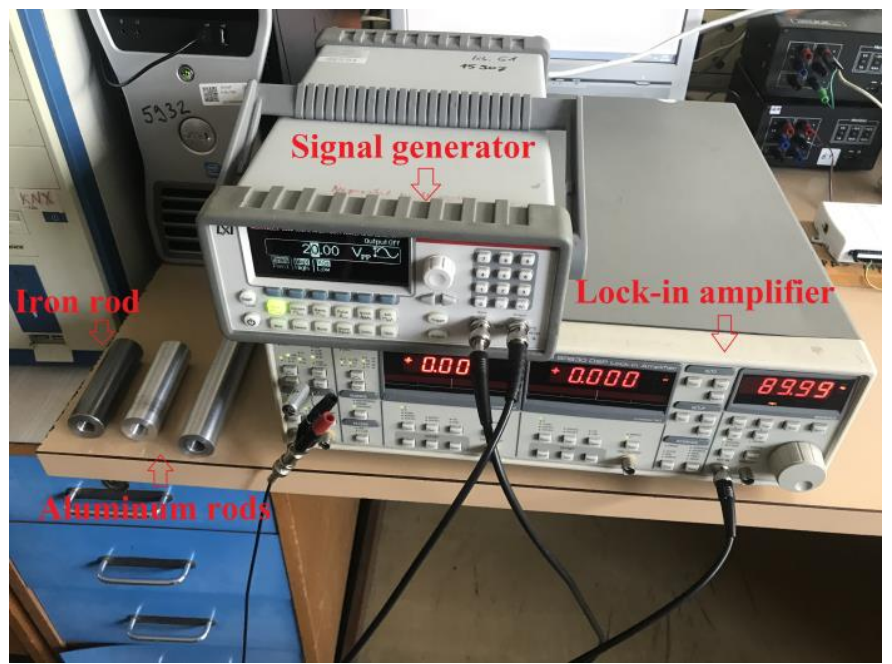

Fig. 14. Experimental set up for rotational eddy current speed sensor - signal generator and lock-in amplifier

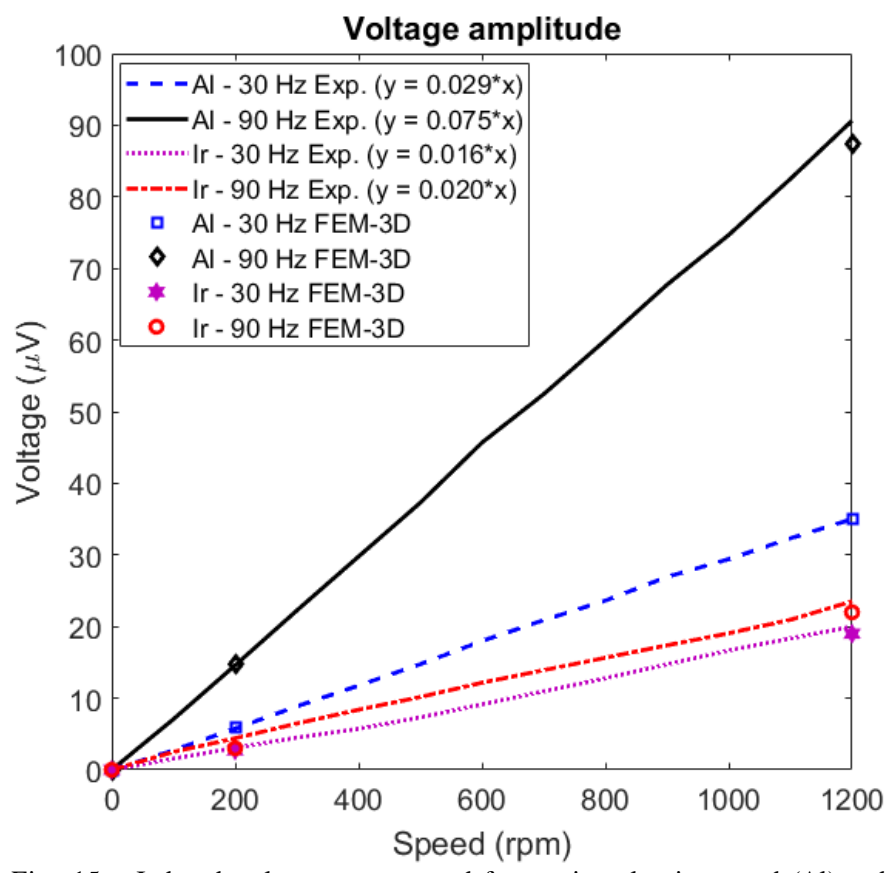

Fig. 15. Induced voltage versus speed for rotating aluminum rod (Al) and rotating iron rod (Ir) - Experiments versus 3D FEM

Fig. 13. Experimental set up for rotational eddy current speed sensor - sensor mounted on rotating rod 
M. Mirzaei, P. Ripka, J. Vyhnanek, A.Chirtsov, V. Grim: Rotational Eddy Current Speed Sen sor,

IEEE Transactions on Magnetics vol.55, no.9, pp.1-10, Sept. 2019, Art no.4003710, 10.1109/TMAG.2019.2918163

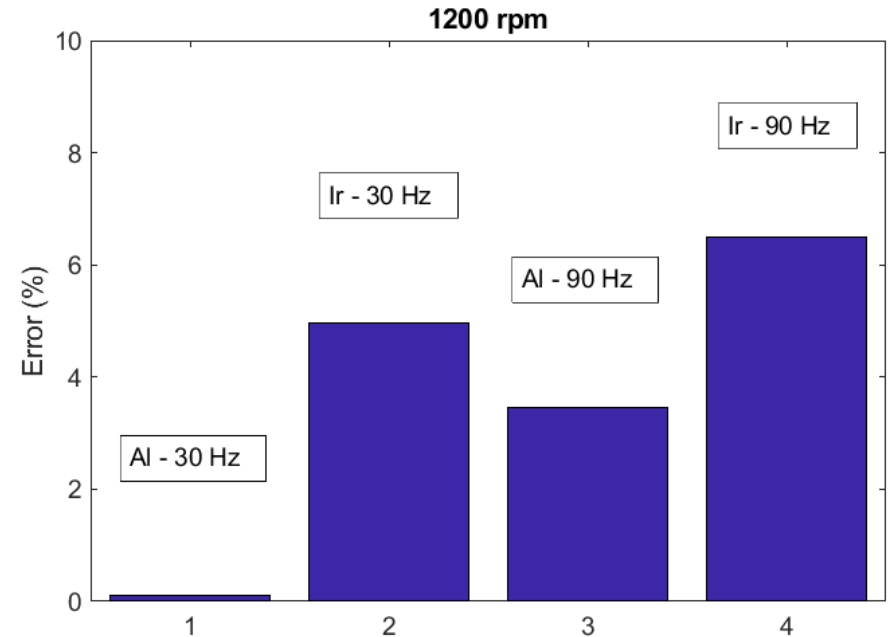

Fig. 16. Error of 3D FEM results relative to measurements

\section{DOUBle LAYER RoD}

Fig. 17 and Fig. 18 show new proposed double layer rod with magnetic flux distribution. Center rod is solid iron and aluminum shell is the second layer. Second layer could be any other nonmagnetic metal such as copper or brass. Double layer moving or rotating part is well known configuration to improve performance of solid rotor rotating induction motor or solid secondary linear induction motors [21]-[22]. It increases equivalent conductivity of rotating rod and causes low magnetic reluctance using high permeability iron part. Double layer rotating rod can be easily manufactured by adding a simple shell or ring to the iron rod.

Rotating rod in Fig. 17 has total outer radius $15 \mathrm{~mm}$ with iron rod radius $13 \mathrm{~mm}$. Iron rod radius is considered fixed, $15 \mathrm{~mm}$ and total outer radius is $16 \mathrm{~mm}$ in Fig. 18 with $1.25 \mathrm{~mm}$ gap and same coils angle as Fig. 18. Both models show improved flux linkages of the pick up coils in comparis on with complete iron rod.

Differential voltage variations versus aluminum shell thickness for fixed rotating rod outer radius $15 \mathrm{~mm}$ is shown in Fig. 19 at $90 \mathrm{~Hz}$ and $1200 \mathrm{rpm}$, which has maximum value, $189 \mu \mathrm{V}$ with aluminum shell thickness $3.5 \mathrm{~mm}$. It shows considerable improvement in the speed sensor output and sensitivity. The 3D and 2D FEM results approve analytical estimation for the speed sensor performance improvement with double layer configuration.

Using higher conductivity aluminumshell or copper s hell could increase the output differential voltage.

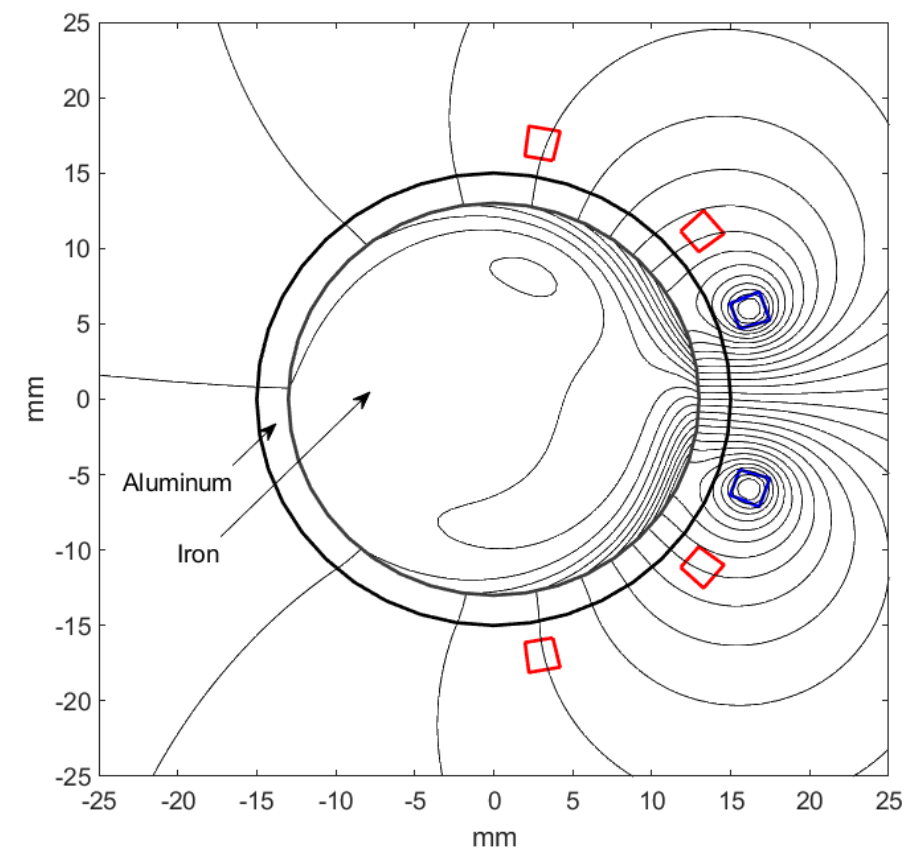

Fig. 17. Magnetic flux distribution at $90 \mathrm{~Hz}$ and $+1200 \mathrm{rpm}$ with double lay er rotating iron (outer radius $13 \mathrm{~mm}$ ) and aluminum shell (with $2 \mathrm{~mm}$ thickness) - First configuration of coils: one excitation coil and two antiserially connected pick up coils - Analytical method

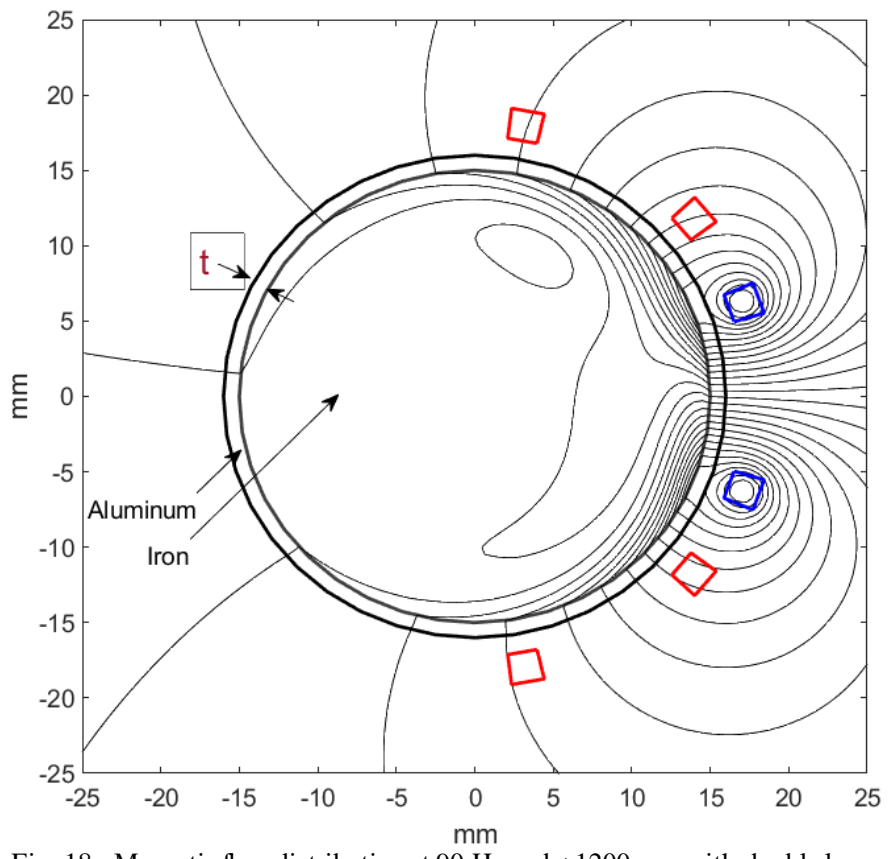

Fig. 18. Magnetic flux distribution at $90 \mathrm{~Hz}$ and $+1200 \mathrm{rpm}$ with double lay er rotating iron (with radius $15 \mathrm{~mm}$ ) and aluminum shell (with $1 \mathrm{~mm}$ thickness) First configuration of coils: one excitation coil and two antiserially connected pick up coils - Analytical method 
M. Mirzaei, P. Ripka, J. Vyhnanek, A.Chirtsov, V. Grim: Rotational Eddy Current Speed Sen sor,

IEEE Transactions on Magnetics vol. 55, no.9, pp.1-10, Sept. 2019, Art no.4003710, 10.1109/TMAG.2019.2918163

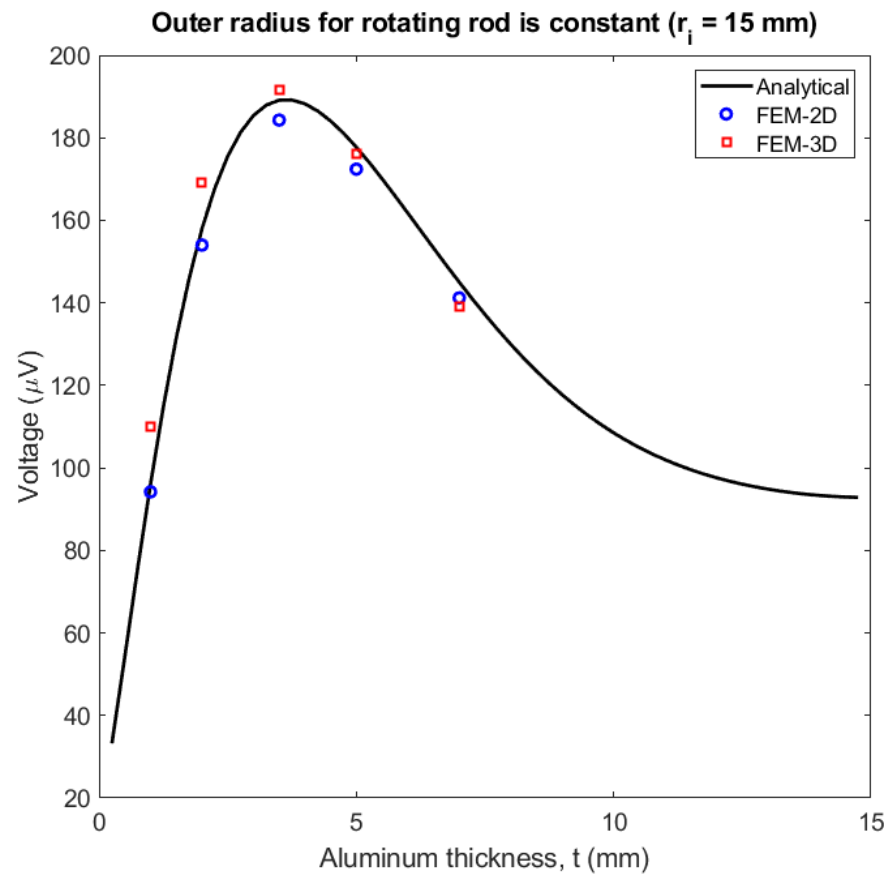

Fig. 19. Variation of differential voltage (amplitude) versus aluminum layer thickness with double layer rotating iron and aluminum shell (with $\mathrm{t} \mathrm{mm}$ thickness as shown in Fig. 18) - fixed total outer radius $15 \mathrm{~mm}$

Fig. 20 shows speed sensor output voltage for double lay er rotating rod with fixed rotating iron rod radius, $15 \mathrm{~mm}$ in comparis on with completely aluminumrod and iron rod with same outer radius at $90 \mathrm{~Hz}$ and $1200 \mathrm{rpm}$. The maximum value for induced voltage is $268 \mu \mathrm{V}$ with aluminum shell thickness $6 \mathrm{~mm}$ in Fig. 20. The induced voltage in double layer rod is considerably higher than completely aluminum rod. The induced voltage in completely iron rod does not considerably increase even with much higher radius as sho wn in Fig. 20.

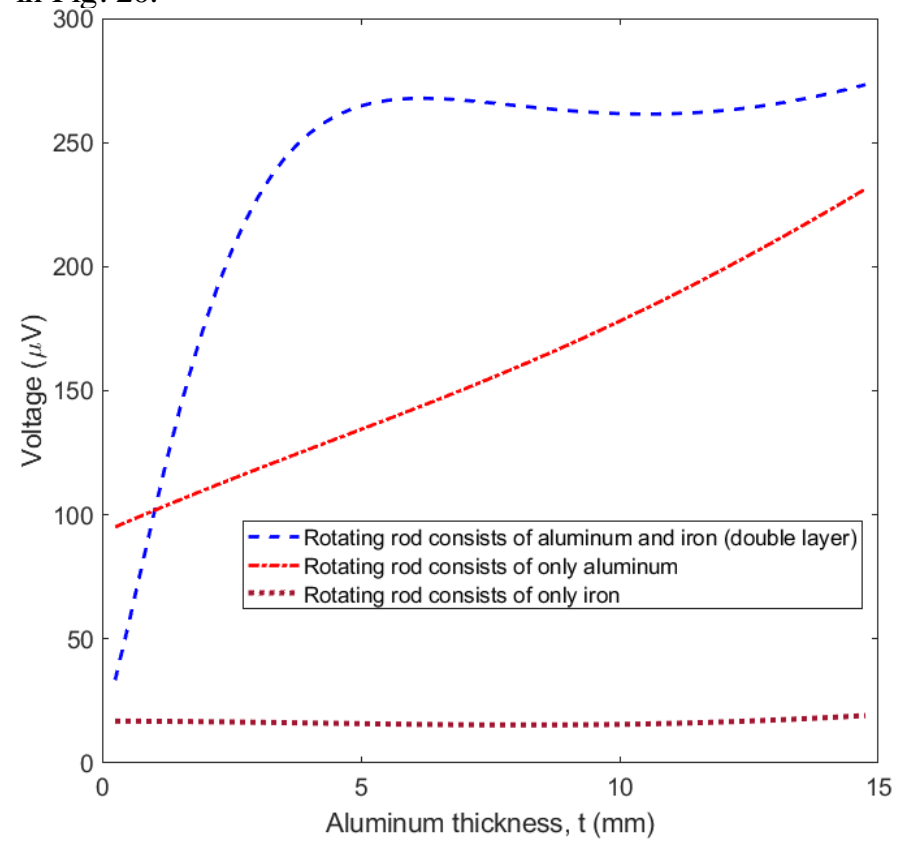

Fig. 20. Variation of differential voltage (amplitude) versus second layer shell thickness (with $\mathrm{t} \mathrm{mm}$ thickness as shown in Fig. 19) - iron rod part has $15 \mathrm{~mm}$ radius - Analytical method

The effect of aluminum shell or ring height is evalu at ed in Fig. 21 and Fig. 22. Fig. 21 shows eddy current distribution for long shell and Fig. 22 shows eddy current distribution for short shell. The calculated differential induced voltage is 110 $\mu \mathrm{V}$ in long shell aluminum model and it becomes $66 \mu \mathrm{V}$ in short shell aluminum model due to the modified path for induced eddy currents [23]-[24].

Fig. 23 presents induced voltage versus relative magnetic permeability, $\mu_{\mathrm{r}}$ for different aluminum shell thickness of double layer rotating rod with fixed outer radius $15 \mathrm{~mm}$ at $90 \mathrm{~Hz}$ and $1200 \mathrm{rpm}$. Induced voltages decrease $56 \%$ for full iron rotating rod with zero aluminums hell thickness and $6.1 \%$ with $1 \mathrm{~mm}$ aluminum shell thickness when $\mu_{\mathrm{r}}$ changes from 50 to 150 . But Induced voltages only increase $0.23 \%$ with $2.35 \mathrm{~mm}$ aluminum shell thickness and $1.23 \%$ with $3.5 \mathrm{~mm}$ aluminum shell thickness. It shows that effect of relative magnetic permeability could be minimized by adjusting aluminum shell thickness. Gradient of induced voltage versus relative magnetic permeability is negative at smallalu min u m shell thickness and it is positive at bigger aluminum shell thickness.

The voltages are rather low, but for only 50-turn coil. Real number of turns can be higher, it is practically limited only by parasitic capacitances. For example, setting number of turn s for excitation coil and pick up coils equal to 1000-turn can increase eddy current speed sensor output with $\mathrm{g}$ a in of 2500 for the same excitation current, as the induced voltage is proportional to the square of number of turns. 
M. Mirzaei, P. Ripka, J. Vyhnanek, A.Chirtsov, V. Grim: RotationalEddy Current Speed Sen sor,

IEEE Transactions on Magnetics vol. 55, no.9, pp.1-10, Sept. 2019, Art no.4003710, 10.1109/TMAG.2019.2918163

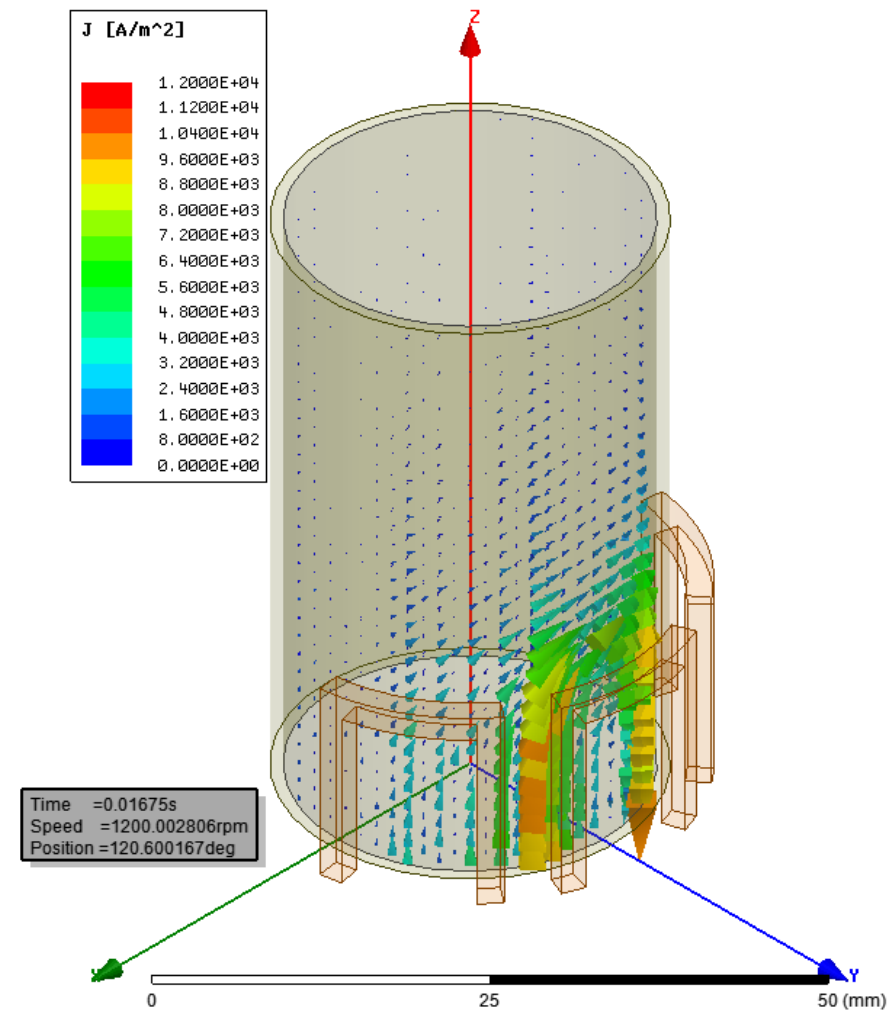

Fig. 21. Eddy currents distribution in the doubly layer rotating iron + aluminum shell at $1200 \mathrm{rpm}$ and $90 \mathrm{~Hz}$ (outer radius of iron is $14 \mathrm{~mm}$ and aluminum shell thickness is $1 \mathrm{~mm}$ ) - long aluminum shell

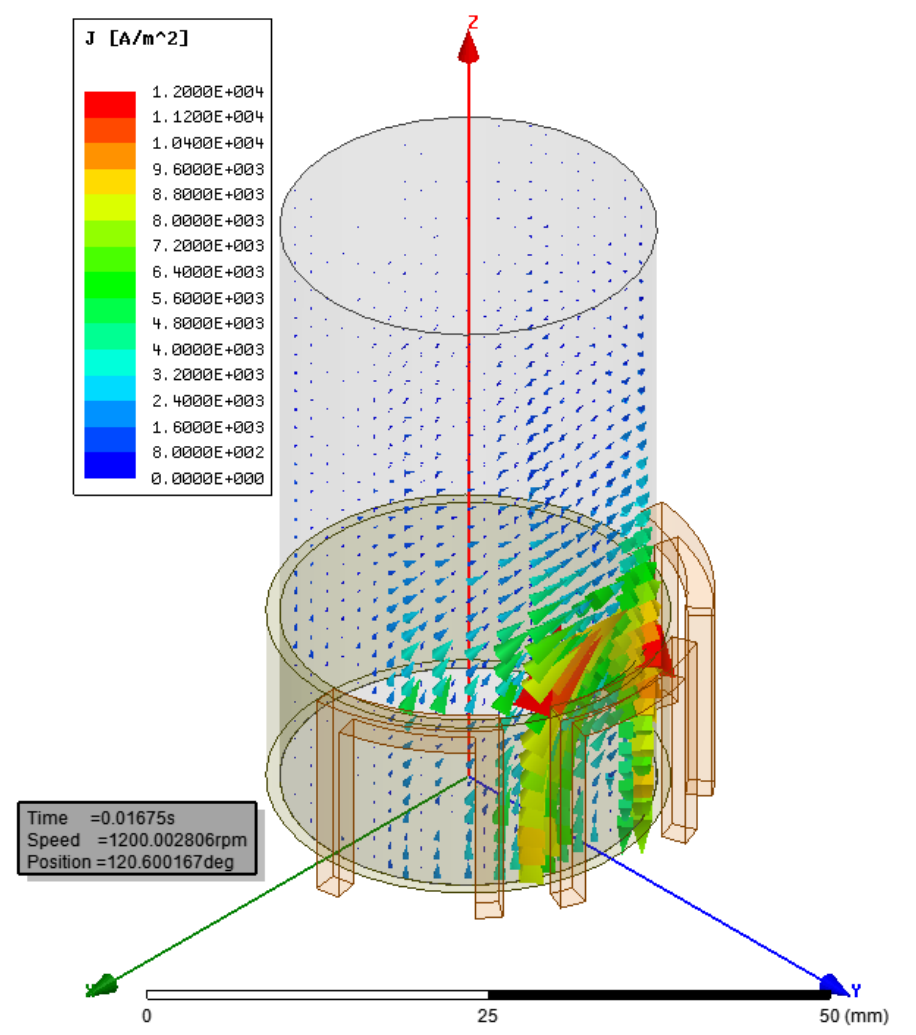

Fig. 22. Eddy currents distribution in the doubly layer rotating iron + aluminum shell at $1200 \mathrm{rpm}$ and $90 \mathrm{~Hz}$ (outer radius of iron is $14 \mathrm{~mm}$ and aluminum shell thickness is $1 \mathrm{~mm}$ ) - short aluminum shell with $30 \mathrm{~mm}$ height

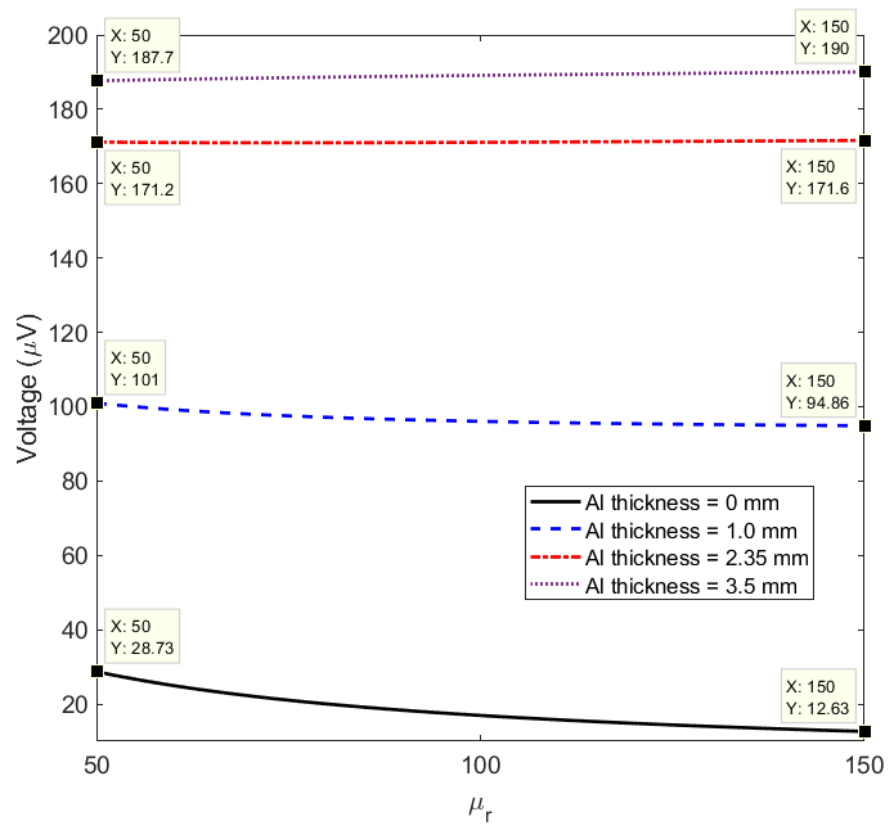

Fig. 23. Variation of differential voltage (amplitude) versus iron rod permeability at different aluminum layer thickness - $1200 \mathrm{rpm}$ and $90 \mathrm{~Hz}-$ Analytical method

\section{CONCLUSION}

A novel rotational eddy current speed sensor was presented. Analytical and numerical FEM calculations were used to analyze and improve the performance of proposed speed sensor. 2D analytical method is faster and more suitable for the design of eddy current speed sensor despite it is less precise in comparis on with 3D FEM for air coil configuration.

Different configurations of rotational speed sensor and parameters were evaluated in this paper. The meas ure ments and calculations have been done until $1200 \mathrm{rpm}$ but the proposed speed sensor is als o suitable for higher speeds as it does not have mechanical and electrical limitations. The whole coils span is less than 180 Deg., which could be installed in one side of rotating rod and it is mechanically contactless with rotating rod.

The double layer rod can significantly improveeddy current speed sensor performance when the rotating rod must be fro $\mathrm{m}$ magnetic steel. It needs only high electrical conductivity nonmagnetic ring or shell, for example made of aluminum or copper. By using the highly conductive non-magnetic shell the sensitivity is improved and it becomes less susceptible to permeability changes.

\section{ACKNOWLEDGMENT}

Authors thank to Mr. Jaroslav Cerny in Department of Measurement in Faculty of Electrical Engineering of Czech Technical University for support to build rotational eddy current speed sensor components. This work was supported in part by Czech Technical University under Grant SGS18/187/OHK3/3T/1. 
M. Mirzaei, P. Ripka, J. Vyhnanek, A.Chirtsov, V. Grim: Rotational Eddy Current Speed Sen sor,

IEEE Transactions on Magnetics vol.55, no.9, pp.1-10, Sept. 2019, Art no.4003710, 10.1109/TMAG.2019.2918163

\section{REFERENCES}

[1] T. Addabbo, M. Di Marco, A. Fort, E. Landi, M. Mugnaini, V. Vignoli, and G. Ferretti, "Instantaneous rotation speed measurement system based on variable reluctance sensors for torsional vibration monitoring," IEEE Trans. Ins. and Meas., ( Early Access ), pp. 1-11, Nov. 2018

[2] N. Fernando, P. Arumugam, and C. Gerada, "Design of a stator for a high-speed turbo-generator with fixed permanent magnet rotor radius and volt-ampere constraints," IEEE Trans. Energy Conv., vol. 33 , no. 3, pp. $1311-1320$, Sep. 2018

[3] P. Ripka, Magnetic Sensors and Magnetometers, Artech House, Jan 1, 2001 - Technology \& Engineering

[4] J. J. Costello, and A. C. Pickard, “A novel speed measurement system for turbomachinery," IEEE Sensors Letters, vol. 2, no. 4, 2018

[5] E. Cardelli, A. Faba, and F. Tissi, "Contact-less speed probe based on eddy currents," IEEE Trans. Mag., 2013, vol. 49, no. 7, pp. 3897 - 3900

[6] T. J. Rocha, H. G. Ramos, A. L. Ribeiro, and D. J. Pasadas, "Evaluation of subsurface defects using diffusion of motion-induced eddy currents," IEEE Trans. Instr. and Meas., vol. 65, no. 5, pp. 1182 - 1187, Dec. 2016

[7] T. Sonoda, R. Ueda, K. Fujitani, T. Irisa, and S. Tatata, "DC magnetic field type eddy current speed sensor detecting cross magnetization field with amorphous core," IEEE Trans. Mag., vol. 21, no. 5, pp. 1732 1734, Sep. 1985

[8] N. Takehira, and A. Tanaka, "Analysis of a perpendicular-type eddycurrent speed meter," IEE Proc. A - Phys. Science, Meas. and Instr., Manag. and Educ.- Rev. , vol. 135 , no. 2, pp. 89 - 94, Feb. 1988

[9] T. Itaya, K. Ishida, A. Tanaka, N. Takehira, and T. Miki, "Eddy current distribution for a rectangular coil arranged parallel to a moving conductor slab," IET Science, Meas. \& Tech., vol. 6, no. 2, pp. 43 - 51, Mar. 2012

[10] T. Itaya, K. Ishida, A. Tanaka, and N. Takehira, "Analysis of a forkshaped rectangular coil facing moving sheet conductors," IET Science, Meas. \& Tech. , vol. 3 , no. 4, pp. 279 - 285, Jul. 2009

[11] A. Tuysuz, M. Flank1, J. W. Kolar, and A. Mutze, "Eddy-current-based contactless speed sensing of conductive surfaces," IEEE 2nd Annual Southern Power Electronics Conference (SPEC), pp. 1 - 6, Dec. 2016

[12] M. Mirzaei, P. Ripka, A. Chirtsov, and J. Vyhnanek, "Eddy current linear speed sensor," IEEE Trans. Mag., vol. 55, no. 1, pp. 1-4, Jan. 2018

[13] J. Rickman, "Eddy current turbocharger blade speed detection," IEEE Trans. Mag., vol. 18, no. 5, pp. 1014 - 1021, Sep. 1982

[14] D. Gerada, X. Huang, C. Zhang, H. Zhang, X. Zhang, and C. Gerada, "Electrical machines for automotive electrically assisted turbocharging ,"IEEE/ASME Trans. Mech., vol. 23, no. 5, pp. 2054 -2065, June 2018

[15] M.-S. Lim, J-M Kim, Y-S. Hwang, J-P Hong, “Design of an ultrahigh-speed permanent-magnet motor for an electric turbocharger considering speed response characteristics," IEEE/ASME Trans. Mech., vol. 22, no. 2 , pp. 774 - 784, Dec. 2017

[16] K.J. Binns, P.J. Lawrenson, and C.W. Trowbridge, The Analytical and Numerical Solutions of Electric and Magnetic Fields, Published by John Wiley \& Sons Ltd., 1992

[17] M. N. O. Sadiku, Numerical Techniques in Electromagnetics, Second Edition, July 12, 2000 by CRC Press, Textbook

[18] K. Davey, "Analytic analysis of single- and three-phase induction motors," IEEE Trans. on Mag., vol. 34, no.5, pp. 3721- 3727, Sept. 1998

[19] D. Schieber, Electromagnetic Induction Phenomena, Springer-Verlag, 1986 - Science

[20] Ansys-Maxwellsoftware, Accessed on 23.01.2019:https://www.ansys.com/products/electronics/ansys-maxwell

[21] S.A. Nasar, L. D. Cid, "Certain approaches to the analysis of singlesided linear induction motors," Proc. of the Inst. of Elect. Eng., vol. 120 , no. 4, pp. 477 - 483, April 1973

[22] J. F. Gieras, and J. Saari, "Performance calculation for a high-speed solid-rotor induction motor," IEEE Trans. Indus. Elect., vol. 59, no. 6 , pp. 2689 - 2700, June 2012

[23] H. Bolton, "Transverse edge effect in sheet-rotor induction motors," Proc. of the Inst. of Elect. Eng., vol. 116, no. 5, pp. 725 - 731, May 1969

[24] H. Seo, J. Lim, G. Choe. J. Choi, and J. Jeong, "Algorithm of linear induction motor control for low normal force of magnetic levitation train propulsion system, "IEEE Trans. on Mag. , vol. 54, no. 11, pp. 1-4, Jul. 2018 , 